\title{
Pollen-Stigma Interactions following Compatible and Incompatible Pollinations in Hazelnut
}

\author{
Cheryl R . H ampson ${ }^{1}$ and Anita $\mathrm{N}$ ina Azarenko ${ }^{2}$ \\ Department of Horticulture, Oregon State University, 4017 Agricultural and Life Sciences Building, \\ Corvallis, OR 97331-7304 \\ Al Soeldner ${ }^{3}$ \\ Department of Botany and Plant Pathology, Oregon State University, 2082 Cordley Hall, Corvallis, \\ OR 97331
}

Additional index words. callose, Corylus avellana, filbert, flowering, fluorescence microscopy, scanning electron microscopy, sporophytic self-incompatibility

\begin{abstract}
Scanning electron microscopy was used to describe pollen-stigma interactions during compatible and incompatible pollinations of hazelnut (Corylus avellana L.), a species possessing sporophytic self-incompatibility. The stigmatic surface is of the dry type and was covered with elongated, rounded papillae. Compatible and incompatible pollen hydrated within 2 hours of pollination. Compatible pollen tubes emerged by 4 hours and grew into the style by 12 hours after pollination. Penetration of stigmatic papillae appeared to be intracellular in some cases. In incompatible pollinations, however, pollen tube emergence was delayed until at least 8 hours. The pollen tubes were distorted and did not penetrate the stigma.
\end{abstract}

Hazelnut trees are anemophilous, monoecious, self-incompatible, and usually dichogamous. Most cultivars grown in the United States are protandrous and bloom in midwinter (December to February) in Oregon. The male flowers are borne in catkins. Female inflorescences lack a perianth and appear as a tuft of red stigmatic styles protruding from the apex of compound buds borne laterally or terminally on shoots or on catkin peduncles. Each female flower bears two styles, and a bud contains a cluster or cymule of 4 to 16 flowers (Thompson, 1979b). Female flowers are receptive at the time of emergence and remain so for up to 3 months if pollination is prevented (Thompson, 1979b).

Cross-pollination is required for good nut set in hazelnuts. At least two different pollinizers are recommended for commercial production to ensure that a sufficient amount of viable, compatible pollen is present when needed, since flowers continue to emerge for several weeks. In addition, warm weather at flowering alters dichogamy by accelerating pollen release more than style exsertion and must be considered during pollinizer selection. The selection of pollinizers is further complicated by the presence of self-incompatibility.

Self-incompatibility, a genetic mechanism enforcing outcrossing and most frequently controlled by a single multi-allelic locus (the $S$ locus), is widespread in angiosperms (Gaude and Dumas, 1987; Heslop-Harrison, 1975). Pollen grains expressing an $S$ allele that is also expressed in the recipient pistil are rejected.

There are two main kinds of self-incompatibility, gametophytic and sporophytic (Gaude and Dumas, 1987; Heslop-Harrison, 1975; Nasrallah et al., 1991). In gametophytic self-incompatibility

Received for publication 31 Aug. 1992. Accepted for publication 20 Apr. 1993. Oregon Agricultural Experiment Station technical paper no. 10,178. This research was funded by the Oregon Filbert Commission. Special thanks to Viki Freeman. The cost of publishing this paper was defrayed in part by the payment of page charges. Under postal regulations, this paper therefore must be hereby marked advertisement solely to indicate this fact.

${ }^{1}$ Graduate research assistant.

${ }^{2}$ Associate professor.

${ }^{3}$ Senior instructor.
(GSI), the pollen's own haploid $S$ genotype is expressed, and pollen tube growth is retarded in the style of flowers bearing the same $S$ allele. GSI is present in Rosaceae, Solanaceae, Liliaceae, and many other families. Fewer families are known to possess sporophytic self-incompatibility (SSI). In SSI, $S$ expression in pollen is controlled by the parental $S$ genotype. This control is believed to be accomplished by the transfer of tapetal proteins, including recognition factors, to cavities in the pollen grain wall during microsporogenesis. SSI is more complex than GSI, because dominance and co-dominance of alleles can occur in pollen, and the dominance hierarchy may differ in pollen and pistil. In SSI, incompatible pollen tubes are arrested on the stigma. In Brassica, impaired adhesion and hydration have also been reported in incompatible pollinations (Gaude and Dumas, 1987; Nasrallah et al., 1991). SSI is correlated with dry stigmas (those bearing an adhesive proteinaceous pellicle lacking copious fluid) and tricellular, short-lived pollen (Brewbaker, 1957). It occurs in Brassicaceae, Compositae, and some other families.

Hazelnuts show SSI (Thompson, 1979a). In all genotypes examined so far, $S$ alleles are codominant in the style and either dominant or codominant in the pollen (Mehlenbacher and Thompson, 1988). Because of dominance relations, reciprocal differences in incompatibility may occur between cultivars, a result that further complicates pollinizer selection. Hazelnuts are an exception to Brewbaker's (1957) correlation, because, unlike typical SSI plants, they have bicellular, potentially long-lived pollen (Heslop-Harrison et al., 1986). Pollen cytology and germination in vitro have been described (Heslop-Harrison et al., 1986).

Knowledge of pollen-stigma interactions in SSI is drawn largely from observations on herbaceous annuals (crucifers and composites). The behavior of hazelnut pollen was of interest since it has atypical pollen cytology for SSI (Heslop-Harrison et al., 1986) and because reports conflict as to whether or not pollen germinates on incompatible styles (Heslop-Harrison, 1986; Thompson, 1979a). Our objective was to examine early pollenstigma interactions of hazelnut, including the appearance of the stigma, the presence of exudate, and the presence and timing of 
pollen hydration, germination, and pollen tube penetration in compatible and incompatible pollinations to characterize incompatibility in this species.

\section{Materials and Methods}

Hazelnut trees were emasculated and enclosed in cages $(2.4 \times$ $2.4 \times 2.4 \mathrm{~m})$ that were covered with white polyethylene on $13 \mathrm{Dec}$. 1991 to prevent pollination. The trees were located at the Vegetable Research Farm, Corvallis, Ore. Branches bearing female flowers were excised from caged trees, brought to the greenhouse in plastic bags, recut under water, and kept in flasks with the cut ends in water. Care was taken not to moisten or bruise the flowers.

Flowers were placed in microporous specimen containers and fixed in 5 parts $37 \%$ formaldehyde: 5 parts glacial acetic acid: 90 parts $70 \%$ ethanol (FAA) (by volume) at room temperature for at least $2 \mathrm{~h}$, then dehydrated in $50 \%, 70 \%$, and $100 \%$ water-acetone solutions, followed by $50 \%, 70 \%$, and $100 \%$ acetonetrichlorotrifluoroethane solutions at $\geq 20 \mathrm{~min}$ per change. Samples were critical-point dried with monochlorotrifluoromethane in a dryer (model CPD-020; Balzers Union, Fürstentum, Liechtenstein) mounted on aluminum planchettes with cement (DUCO; Devcon Corp., Wood Dale, Ill.) and coated with $200 \mathrm{~nm}$ of 60:40 (by weight) gold : palladium alloy in a vacuum evaporator (model VE-10; Varian Corp., Palo Alto, Calif.) at $1.33 \mathrm{mPa}$. The flowers were viewed on a scanning electron microscope (SEM) (model 1000A; AmRay, Bedford, Mass.) operated at 7 or $10 \mathrm{kV}$ at Oregon State Univ. Samples that became charged in the SEM under these conditions were recoated with $\approx 15 \mathrm{~nm}$ of gold in a sputter coater (type S150B; Edwards, Crawley, West Sussex, England) at 1.33 $\mathrm{Pa}$. Another set of flowers fixed in FAA was checked for evidence of pollen tube growth in the style. Styles were squashed in aniline blue dye (Thompson, 1979a) and examined with a fluorescence microscope (Leitz Laborluxs, Leica Microscopy, Wetzlar, Germany) equipped with an ultraviolet light source. Callose fluoresces under these conditions.

A preliminary experiment was conducted with 'Barcelona' trees on 22 Jan. 1992 to compare fresh- and fixed-sample appearance and to determine whether ambient laboratory conditions induced stylar desiccation. In this study, some styles were examined before pollination and within $1 \mathrm{~h}$ of excision. Pollinated and unpollinated styles were also examined after $2 \mathrm{~h}$ at ambient conditions $(\approx 25 \mathrm{C})$ with or without being covered with plastic bags to retard desiccation. Electron microscopy was performed as outlined previously, except that samples were observed at $5 \mathrm{kV}$. Specimens kept at ambient conditions underwent an unacceptable degree of desiccation and extensive papillar collapse within $2 \mathrm{~h}$, whether pollinated or not, but drying was prevented by covering them with plastic bags.

'Ennis' hazelnut trees planted in 1987 were used in the main experiment. On 15 Feb. 1992, enough branches sufficient to obtain 250 to 300 pistillate buds were cut, placed in plastic bags, and brought immediately into a greenhouse. The greenhouse was equipped with misting devices and was maintained at $18 / 15.5 \mathrm{C}$ day/night under natural light. The branches were recut under water, placed in flasks of water, and divided into three groups. One set was pollinated, using the tip of the smallest finger, with compatible ('Willamette') pollen and one with incompatible ('Ennis') pollen and the last set (control) was touched but not pollinated. The flasks were put on the greenhouse floor under three wooden frames draped with plastic such that the branches were in a humid environment but without direct exposure to the mist jets. Flowers were sampled at various intervals from $2 \mathrm{~h}$ up to $28 \mathrm{~h}$ after pollination. The experiment was repeated on 17 and 20 Feb. 1992.

Pollen, obtained by allowing mature catkins to dehisce overnight in the laboratory, was stored at $-20 \mathrm{C}$ before use. Percentage germination, scored after $16 \mathrm{~h}$ on a $20 \%$ sucrose medium solidified with $1 \%$ agar, was $59 \%$ for 'Emus' and $76 \%$ for 'Willamette'. Such values are in the normal range for these varieties.

\section{Results and Discussion}

Comparison of fresh and fixed samples. The entire stylar surface was covered with rounded, basally attached papillae and appeared to be of the dry type on fresh samples, a characteristic consistent with other species having SSI systems (Fig. 1a). Fixed, coated specimens did not show the differences in surface tones visible on fresh samples and sometimes slight wrinkling of papillar tips occurred, but their general appearance was only slightly affected by fixation (Fig. 1b). There was no evidence on these specimens of discrete patches of electron-lucent and electron-dense materials, such as found by Wetzstein and Sparks (1989) on pecan stigmas

Several differences were noted between fresh and fixed samples. Moderate papillar collapse was observed on many fresh, uncoated specimens (with or without pollination), but rarely on fixed samples. Whether the collapse was induced by the vacuum in the electron microscope, or papillae became "plumped up" again during passage through the fluid fixatives, or both was not clear. In contrast, the appearance of dry (collapsed) or hydrated (plump) pollen on stigmas was not altered by the fixation process (data not shown). Some of the applied pollen was lost during fixation, as experienced by previous workers (Heslop-Harrison et al., 1986; Thompson, 1979a), but much remained attached. Uncoated, pollinated stigmas frequently became charged and difficult to photograph after several minutes in the SEM.

On 11 Feb. 1992, we viewed a limited number of fresh, uncoated 'Ennis' flowers in a field emission SEM (model S-4100; Hitachi, Tokyo) (operated at $1.0 \mathrm{kV}$ ) during a demonstration hosted by Palmborg Associates, Mercer Island, Wash. An unpollinated stigma surface is shown in Fig. 1c. The high contrast visible on the papillar surface is caused by some difference in electron-scattering properties, such as a difference in hydration. The change is quite distinct and was not visible on uncoated samples viewed in our SEM (Fig. 1a). Moderate papillar collapse also occurred on fresh samples in the Hitachi SEM (data not shown).

Dry, uncoated pollen (Fig. 2a) did not differ in appearance from coated samples observed previously (data not shown). The pollen is triporate with circular pores, as previously described (Heslop-Harrison et al., 1986). The exine surface is microechinate (Fig. 2b) (Micic et al., 1988), a feature shared by pecan, another wind-pollinated species (Wetzstein and Sparks, 1985).

Using fixed, coated specimens in our main study, therefore, imposed certain limitations. We could not describe pellicle characteristics because some surface detail was not visible. Papillar collapse, observed as a consequence of pollination in Carya (Wetzstein and Sparks, 1989), Raphanus (Dickinson and Lewis, 1973) and many other species, could not be interpreted unambiguously. Nevertheless, we are confident that gross morphological events, such as pollen tube emergence and penetration, could be described adequately.

Time course of compatible and incompatible pollinations. The cool, humid conditions in the mist greenhouse prevented stylar desiccation and more closely resembled field conditions during hazelnut flowering than did the laboratory environment. Field 


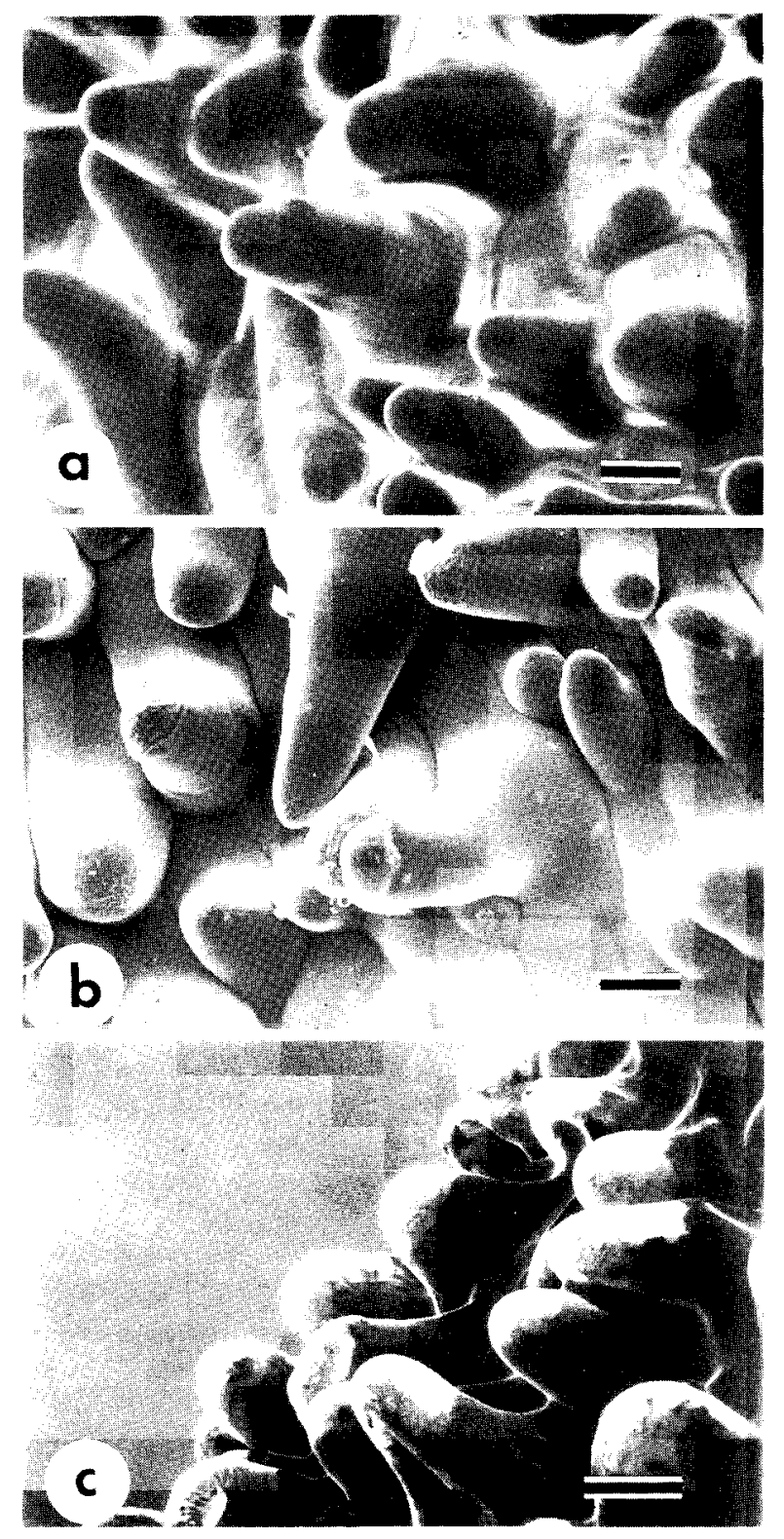

Fig. 1. Scanning electron micrographs of the stigmatic surface of a hazelnut flower before pollination. (a) Fresh, uncoated specimen in an AmRay 1000A scanning electron microscope (SEM). No fluid exudate is discernible on the surface. (h) Fixed, coated specimen in an AmRay 1000A SEM. (c) Fresh, uncoated stigmatic surface of an unpollinated hazelnut flower in an Hitachi S-4100 SEM. Note differences in the color contrast on the papillar tips, not visible in Fig. 2 a or b. Bar $=10 \mu \mathrm{m}$. temperatures at flowering are normally lower than those in the greenhouse, however, and may retard the events described here.

A cluster of unpollinated styles is shown in Fig. 3a. The stylar surfaces were covered with plump, elongated papillae (Fig. 3b). No contaminating pollen was seen on any of the unpollinated flowers, and the papillae showed no signs of desiccation over the course of the experiment.

Two hours after pollination, most of the compatible pollen had hydrated and a few grains showed protruding pores, an early sign of germination (Fig. 4a). By $4 \mathrm{~h}$ after pollination, many pollen tubes had emerged (Fig. 4b), and some appeared to be penetrating papillar cells. Pollen tubes did not necessarily emerge from the pore nearest the stigma, a situation also observed in Raphanus (Dickinson and Lewis, 1973). An unknown substance adhering to some pollen tubes and papillae was visible (Fig. 4b, arrows).

Due to the high relief of the stigmatic surface, determining the site of pollen tube penetration and whether a tube was penetrating a papillar cell or merely appressed to it was sometimes difficult. Fig. 4c illustrates that penetration of the papillae is intracellular, at least some of the time. In crucifers, pollen tubes penetrate the papillar cell wall and grow to the base without entering the protoplast (Dickinson and Lewis, 1973; Kanno and Hinata, 1969; Nasrallah et al., 1991). Pollen tubes penetrate at the base of adjacent papillae in Carya (Wetzstein and Sparks, 1989), Ulmus (Bob et al., 1986), and Cosmos bipinnatus Cavi (Knox, 1973) but intracellularly in self-compatible ragweed (Ambrosia tenuifolia Sprengel) (Knox, 1973). That hazelnut pollen tubes grow intracellularly down the style is unlikely since pollen tube growth in the style is intercellular in all plants studied (Gaude and Dumas, 1987; Nasrallah et al., 1991).

Although many pollen tubes were present by $12 \mathrm{~h}$ after pollination and thereafter (Fig. 4d), some grains remained hydrated without ever germinating, or germinated but did not penetrate the stigma. Germination without penetration was also seen in compatible Cosmos matings (Knox, 1973).

Like compatible pollen, incompatible pollen had hydrated within 2 h (Fig. 5a). Some grains remained completely collapsed; these may have been nonviable. Impaired adhesion and hydration of incompatible pollen have been reported in some, but not all, crucifers (Dickinson and Lewis, 1973; Gaude and Dumas, 1987; Sarker et al., 1988). Hydration is unlikely to be limiting under field conditions normally experienced by hazelnuts during flowering. No change was observed until $8 \mathrm{~h}$ after pollination, when pollen tubes emerged from a very few grains.

An amorphous substance adhering to the pollen grains and papillae could be seen in several electron micrographs (Fig. 5b), including several from the compatible pollinations, but was never

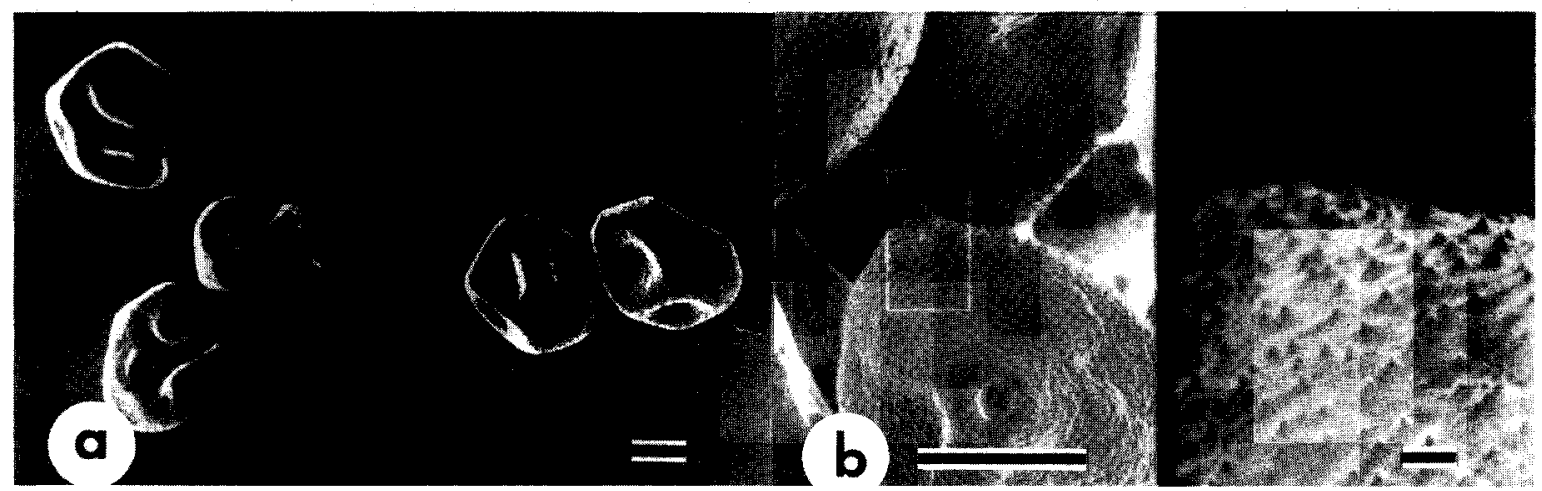

Fig. 2. Fresh, uncoated hazelnut pollen. (a) Appearance of pollen after release from anthers. Bar $=10 \mu \mathrm{m}$. (b) Microechinate surface of pollen grains (bar $=10 \mu \mathrm{m})$ and higher-magnitication view of boxed area $(\mathrm{bar}=1 \mu \mathrm{m})$. 


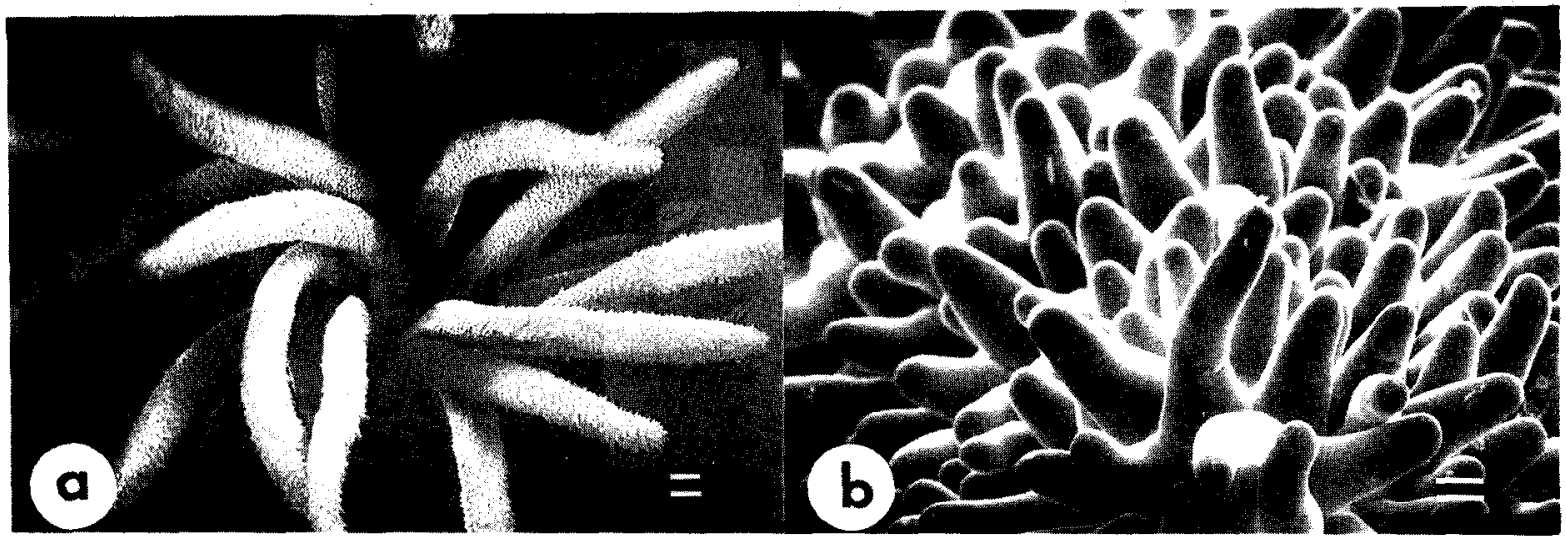

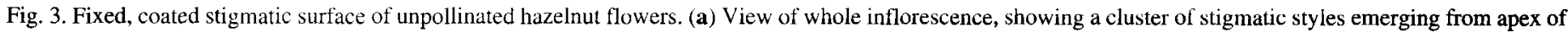
bud. Bar $=100 \mu \mathrm{m}$. (b) Stigmatic surface, bearing numerous papillae, as viewed from tip of style. Bar $=10 \mu \mathrm{m}$.

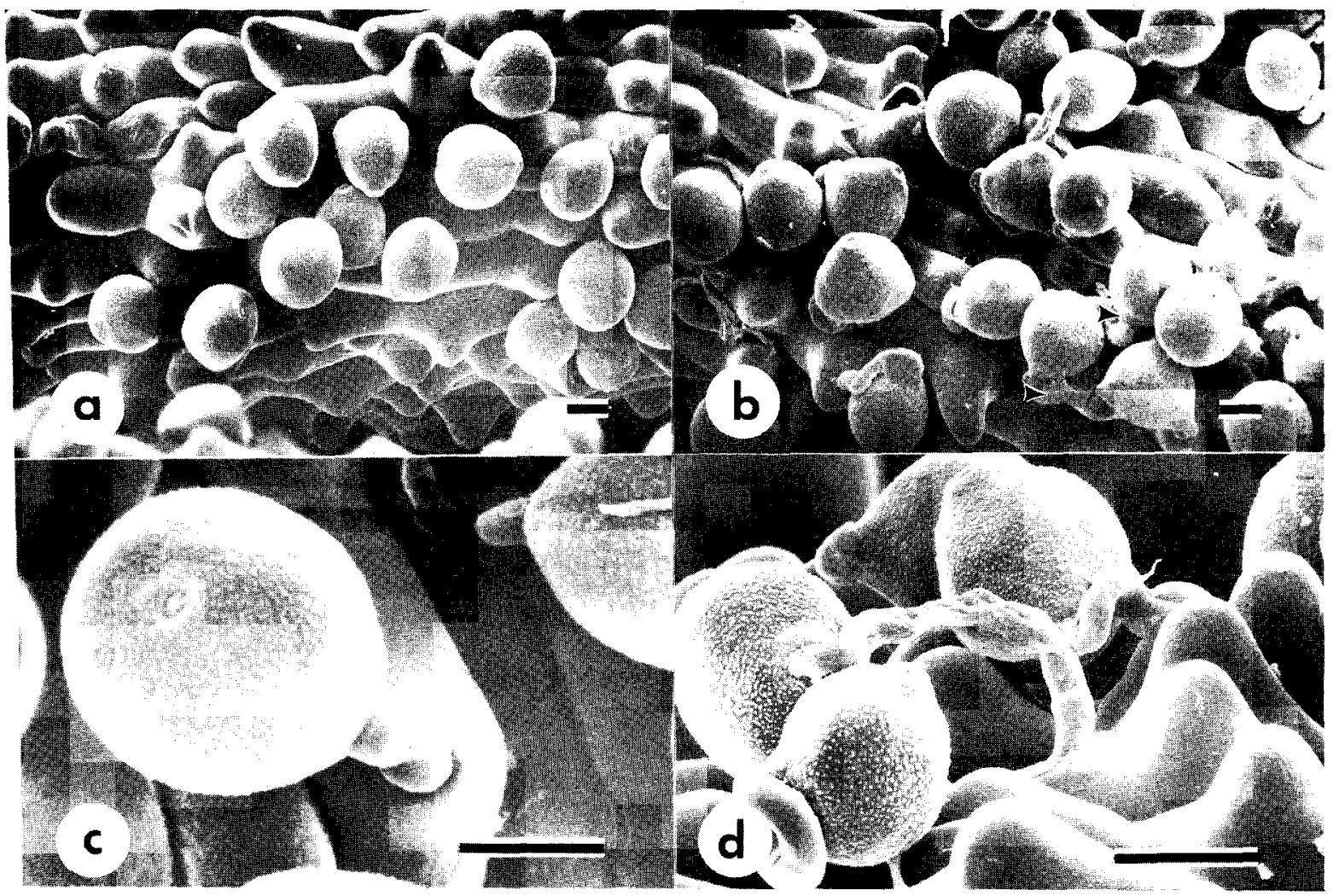

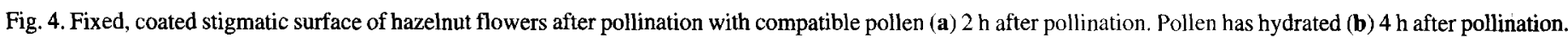
Several pollen tubes have emerged. An unidentified substance can be seen adhering to some pollen tubes (arrows). (c) Pollen tube penetrating papilla $8 \mathrm{~h}$ after pollination. (d) Germinated pollen $12 \mathrm{~h}$ after pollination. Bars $=10 \mu \mathrm{m}$.

observed on unpollinated samples. Both exine- and intine-held pollen proteins quickly diffuse out of the grains during hydration and later steps in pollen germination and fuse with substances on the stigmatic surface (Gaude and Dumas, 1987; Heslop-Harrison, 1975). In hazelnuts, gelatinized pectins are also released from pollen grain apertures (Heslop-Harrison et al., 1986). In fresh samples, both in our preliminary experiment and with the Hitachi SEM (Fig. 5c), we observed a viscous-appearing substance as early as our first sampling time $(2 \mathrm{~h})$. Similar observations have been reported previously (Gaude and Dumas, 1987; Knox, 1973; Roberts et al., 1979). Possibly, this substance is denatured during fixation and dehydration and takes on the appearance seen in Fig. $4 \mathrm{~b}$ and Fig. $5 \mathrm{~b}$.

Some pollen tubes were present after $18 \mathrm{~h}$ in incompatible matings and after $4 \mathrm{~h}$ in compatible matings. Heslop-Harrison et al.
(1986) noted that incompatible hazelnut pollen failed to germinate, but did not specify the time of incubation. Thompson (1979a) reported abundant germination without penetration in samples viewed with fluorescence microscopy. In our experiments, no tubes were observed to penetrate the stigmatic surface and some appeared to be coiling (Fig. 5d). Many pollen grains remained hydrated without showing any signs of pollen-tube emergence throughout the study. Low percentage germination, delayed germination, and coiled pollen tubes were seen in incompatible matings in Cosmos (Knox, 1973). In Raphanus, germination was blocked in $60 \%$ of incompatible pollen without any visible ultrastructural change (Dickinson and Lewis, 1973).

Results from the squashed styles stained with aniline blue generally supported SEM observations. No evidence for penetration of the style was found in incompatible pollinations. Coiled, 


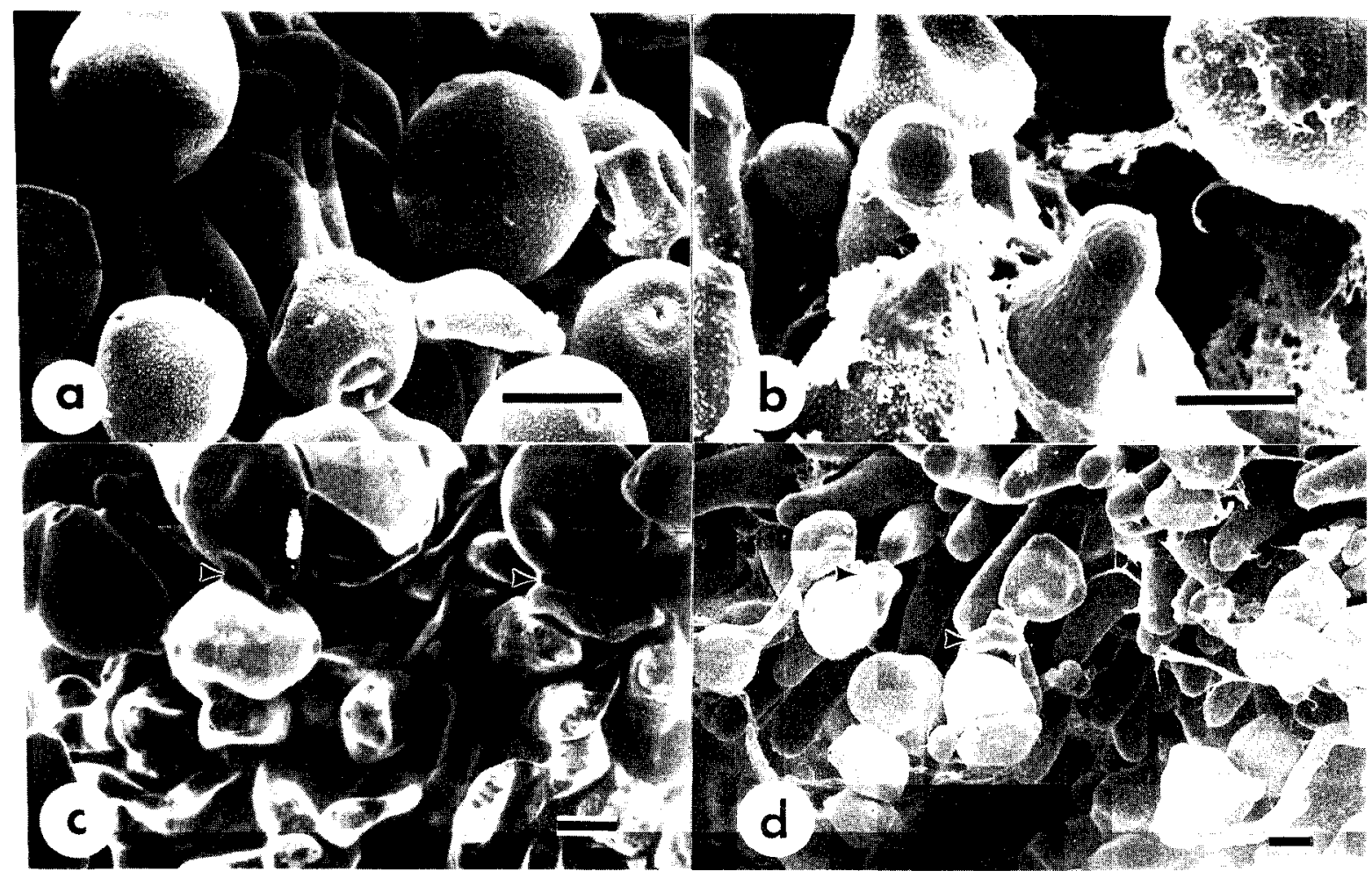

Fig. 5. Stigmatic surface of hazelnut flowers after pollination with incompatible pollen. (a) Fixed sample $2 \mathrm{~h}$ after pollination. Pollen shows varying degrees of hydration. (b) Fixed sample $12 \mathrm{~h}$ after pollination showing unidentified substance adhering to pollen grains and papillae. (c) Fresh, uncoated sample $5 \mathrm{~h}$ after pollination. A smooth-looking substance is visible between some adjacent pollen grains or between pollen grains and papillae (arrows). (d) Fixed sample, $18 \mathrm{~h}$ after pollination. Pollen tubes are visible but do not appear to have entered the stigmatic papillae, and some appear coiled (arrows). Bars $=10 \mu \mathrm{m}$.

bulbous, or tangled pollen tubes characteristic of incompatible reactions in hazelnut (Mehlenbacher and Thompson, 1988; Thompson, 1979a) were present on the stigmatic surface at $12 \mathrm{~h}$ and later. In compatible crosses, penetration of the style (long, parallel pollen tubes punctuated with callose plugs) was visible sometimes at $12 \mathrm{~h}$, or more readily at $18 \mathrm{~h}$ and later. Although a few pollen tubes appeared to be entering stigmatic papillae as early as $4 \mathrm{~h}$ after pollination on electron micrographs, many pollen tubes must penetrate some distance into the style to be easily identifiable on stylar squashes.

Papillar callose is a hallmark of SSI (Gaude and Dumas, 1987; Nasrallah et al., 1991). A low and variable number of papillae in unpollinated and compatibly pollinated hazelnut styles contained small callose deposits, visible as shallow cups fluorescing in papillar tips. These deposits may be normal, but are more likely a response to mechanical damage during handling (touching) during pollination. In incompatible matings, many papillae contained callose after $24 \mathrm{~h}$, either in the tips or throughout the inside of the papillar cell. Whether such callose deposition was limited to papillae in contact with incompatible grains could not be determined from squashed styles. No callose buildup or occlusion occurred in ungerminated pollen grains. Pollen tubes fluoresced brightly.

The appearance of papillar callose in our samples was the same as in photographs of Heslop-Harrison et al. (1986), who induced callose production in hazelnut papillae with incompatible pollen or eluates thereof. The callose deposition response in hazelnut papillae appears to be less dramatic than in crucifers, composites, or Ulmus. In Raphanus, Ulmus, and Cosmos, callose deposition in papillae, pollen grains, or pollen tubes was marked in incompatible crosses, although, in Ulmus and Cosmos, papillar callose occurred sporadically and to a lesser extent in compatible matings, too (Bob et al., 1986; Dickinson and Lewis, 1973; Knox, 1973). If considerable incompatible pollination occurs in the field with hazelnut, occlusion of papillae with callose would be disadvantageous for subsequent compatible pollination and nut set. We do not know whether such callose deposition is reversible.

Our findings support the idea that stigmatic arrest of incompatible pollen and papillar callose production are characteristic features of SSI, although tricellular, short-lived pollen (Brewbaker, 1957) may not be. As in many other SSI species, the stigmatic surface of hazelnut is of the dry type. Incompatible pollen either fails to germinate or germinates belatedly and fails to penetrate the stigma.

\section{Literature Cited}

Bob, C.F., B.L. Redmond, and D.F. Karnosky. 1986. On the nature of intraand interspecific incompatibility in Ulmus. Amer. J. Bot. 73:465-474.

Brewbaker, J.L. 1957. Pollen cytology and self-incompatibility systems in plants. J. Hered. 48:271-277.

Dickinson, H.G. and D. Lewis. 1973. Cytochemical and ultra-structural differences between intraspecific compatible and incompatible pollinations in Raphanus. Proc. Royal Soc. London B 183:21-38.

Gaude, T. and C. Dumas. 1987. Molecular and cellular events of self-incompatibility. Intl. Rev. Cytol. 107:333-366.

Heslop-Harrison, J. 1975. Incompatibility and the pollen-stigma interaction. Annu. Rev. Plant Physiol. 26:403-425.

Heslop-Harrison, Y., J.S. Heslop-Harrison, and J. Heslop-Harrison. 1986. Germination of Corylus avellana L. (hazel) pollen: Hydration and the function of the oncus. Acta Bot. Neerlandica 35:265-284

Kanno, T. and K. Hinata. 1969. An electron microscopic study of the barrier against pollen-tube growth in self-incompatible Cruciferae. Plant Cell Physiol. 10:213-216.

Knox, R.B. 1973. Pollen wall proteins: Pollen-stigma interactions in ragweed and Cosmos (Compositae). J. Cell Sci. 12:421-443. 
Mehlenbacher, S.A. and M.M. Thompson. 1988. Dominance relationships among S-alleles in Corylus avellana L. Theoretical Applied Genet. 76:669-672.

Micic, N., D. Jarebica, and Z. Cmelik. 1988. Morphological characteristics of the exine of hazel pollen (in Serbo-Croatian). Jugoslovensko Vocarstvo 22:97-103. (Plant Breeding Abstr. 60:768; 1990).

Nasrallah, J.B., T. Nishio, and M.E. Nasrallah. 1991. The self-incompatibility genes of Brassica: Expression and use in genetic ablation of floral tissues. Annu. Rev. Plant Physiol. Plant Mol. Biol. 42:393-422.

Roberts, I.N., A.D. Stead, D.J. Ockendon, and H.G. Dickinson. 1979. A glycoprotein associated with the acquisition of the self-incompatibility system by maturing stigmas of Brassica oleracea. Planta 146:179-183.
Sarker, R.H., C.J. Elleman, and H.G. Dickinson. 1988. Control of pollen hydration in Brassica requires continued protein synthesis, and glycosylation is necessary for intraspecific incompatibility. Proc. Natl. Acad. Sci. USA 85:4340-4344.

Thompson, M.M. 1979a. Genetics of incompatibility in Corylus avellana L. Theoretical Applied Genet. 76:669-672.

Thompson, M.M. 1979b. Growth and development of the pistillate flower and nut in 'Barcelona' filbert. J. Amer. Soc. Hort. Sci. 104:427-432.

Wetzstein, H.Y. and D. Sparks. 1985. Structure and in vitro germination of the pollen of pecan. J. Amer. Soc. Hort. Sci. 110:778-781.

Wetzstein, H.Y. and D. Sparks. 1989. Stigma-pollen interactions in pecan. J. Amer. Soc. Hort. Sci. 114:355-359. 